\title{
Physical Attractiveness and Altruism in Two Modified Dictator Games
}

\author{
Manpal Singh Bhogal, Niall Galbraith, and Ken Manktelow
}

University of Wolverhampton

\begin{abstract}
Several studies find that male individuals are more altruistic toward attractive women, suggesting altruism may serve as a courtship display. Many studies exploring this phenomenon have used vignettes and facial images. We tested the sexual selection hypothesis as an explanation for altruistic behavior, where players played the dictator game with "live" participants. Two studies were conducted (Study 1, n à 212; Study 2, $n$ à 188) where we manipulated stakes and anonymity between participants to explore the relationship between the dictator's allocations and their perceived attractiveness of the recipient. We found no relationship between attractiveness and altruism. Dictators were consistently fair when allocating stakes, irrespective of the recipients' attractiveness.
\end{abstract}

\section{Altruism in human mating}

Altruism ${ }^{1}$ is defined as behavior that is costly to the altruist yet beneficial to the receiver (Trivers, 1971). Explaining altruism toward non-kin has been problematic from an evolutionary, and economic perspective, often being referred to as an evolutionary puzzle (Hamilton, 1963; see Kurzban, Burton-Chellew, \& West, 2015, for a review on the evolution of altruism). Recent research has applied sexual selection theory to explain the evolution of altruism toward non-kin (e.g., Barclay, 2010; Farrelly, Lazarus, \& Roberts, 2007; Phillips, Barnard, Ferguson, \& Reader, 2008).

Sexual selection theory suggests that behavioral traits evolve through intra- and intersexual competition. Intersexual competition suggests that traits which increase our reproductive success are selected by sexual selection, commonly referred to as female choice (Workman \& Reader, 2014). These traits increase one's attractiveness in the mating market, thus providing one with a reproductive advantage over others. Sexual selec-tion theory posits that the purpose of altruism is to attract mates, as altruism is considered a sexually selectable trait, evolved to attract the opposite sex (Miller, 2007; Tessman, 1995). Sexually selectable traits increase our mate value, or appeal in the mating market, leading to increased reproductive success. As a result, men should display altruistic traits more often than women, perhaps because they signal a willingness to share resources, signaling commitment toward a partner, thus raising one's value in the mating market (Barclay, 2010).
Tessman (1995) argued that men use altruism as a mating signal, as it relays a man's quality as a partner and future parent. According to parental investment theory (Trivers, 1972), women place a greater impor-tance on a man's ability to gain and share resources than on attractiveness alone, whereas men tend to focus on physical attractiveness more than women do (Buss, 1989). As a result, women should value altruistic traits, especially as women invest far more than men into offspring. Mating with an altruistic man increases the likelihood that future offspring will inherit altruistic tendencies, thus increasing the future offspring's chances of attracting a mate (Anderson, 1994). Investing in a man who possesses altruistic traits is beneficial in child-rearing, increasing survival as well as relationship quality (Kokko, 1998). In order to reduce the risk of abandon-ment, and increase the likelihood of securing resources for future offspring, it is crucial for a woman to choose a mate who possesses altruistic tendencies (Trivers, 1971). In support, women more than men place a greater emphasis on cooperative tendencies (Buss, 1989). Fur-thermore, women prefer to date altruistic men compared to nonaltruistic men, particularly when seeking long-term partners (e.g., Barclay, 2010; Farrelly, 2011, 2013; Farrelly, Clemson, \& Guthrie, 2016). Sharing may be seen as a mechanism whereby men show off their resources in order to attract a mate, increase their reputation, and consequently increasing their mate value (Wood \& Hill, 2000). Because men also offer a substan-tial level of parental investment in terms of resource 
acquisition and sharing (Kaplan \& Hill, 1985), men should be more altruistic toward women they consider attractive. In turn, women should aim to secure mates who display altruistic behavior. In support, several stu-dies find that men exhibit altruism as a courtship display, particularly toward attractive women (Goldberg, 1995; Iredale, Van Vugt, \& Dunbar, 2008; Oda, Shibata, Kiyonari, Takeda, \& Matsumoto-Oda, 2013; Van Vugt \& Iredale, 2013).

Costly signaling theory has been used to explain public displays of altruism, signaling one's ability to confer the benefits associated with altruistic behavior (Zahavi \& Zahavi, 1997). Women are sensitive to cues that relay both protection of a mate and future offspring (Brase, 2006). Altruism is attractive because it signals concern for others (Barclay, 2010). Furthermore, recent evidence suggests that sexual/dating intention are drivers of altruism in men (sexual intention leads to higher altruism and cooperation in men; see Bhogal, Galbraith, \& Manktelow, 2016a). As a result, we should expect men to showcase altruism toward attractive women in a variety of contexts.

\section{The attractiveness halo effect and altruism in game-theoretic frameworks}

The attractiveness halo effect is prevalent in several contexts, suggesting physically attractive people are evaluated more positively than unattractive people (see Dion, Berscheid, \& Walster, 1972; Langlois et al., 2000; Lorenzo, Biesanz, \& Human, 2010, see Maestripieri et al., 2016 for a review on the influence of physical attractiveness on prosocial behavior). Research into dat-ing advertisements suggests that men evaluate women with an attractive profile picture more positively than women with unattractive profile pictures, signifying the power of attractiveness on first impressions (Bak, 2010). We are keen to engage with attractive members of the opposite sex as they assist in the mating process (Maner et al., 2003). We should therefore expect people to be more altruistic toward those to whom they are attracted.

The sexual selection hypothesis has been used to explore the evolution of altruism within a variety of economic games, such as the prisoner's dilemma and the ultimatum game. Researchers have found that men and women are more altruistic and cooperative toward physically attractive players (e.g., Andreoni \& Petrie, 2008; Farrelly et al., 2007; Kahn, Hottes, \& Davis, 1971; Mulford, Orbell, Shatto, \& Stockard, 1998; Solnick \& Schweitzer, 1999; Zaatari, Palestis, \& Trivers, 2009). Furthermore, offers made by women in ultimatum games are accepted more often than offers made by men (Eckel \& Grossman, 2001). Men behave more altruistically toward, and in the presence of, attractive women within a variety of contexts (see Eagly \& Crowley, 1986, for a meta-analysis; Goldberg, 1995; Iredale et al., 2008).

Many studies investigating the sexual selection hypothesis in explaining altruism have involved hypothetical scenarios, vignettes, facial images, or online simulations (e.g., Barclay, 2010; Bhogal et al., 2016a; Rosenblat, 2008; Shinada \& Yamagishi, 2014; Solnick \& Schweitzer, 1999). An advantage of these methods is that they exert control over the extraneous factors that influence decision making. However, they also limit the physical cues available to participants that are avail-able in everyday decision making (Fontelle, Phillips, \& Lane, 1985). In addition, much of the literature involves self-report measures, eliciting socially acceptable rather than actual behavior (Baldwin, 1992). Little research has investigated the role of physical attractiveness in game-theoretical situations where participants are playing with real people, having additional physical cues available that are not present in photographs and online simulations. The research reported in this article aimed to investigate the role of physical attractiveness in altru-ism when players can see an actual participant, aiming to replicate the strong effect found in previous literature by altering the framework in which these hypotheses can be tested.

Many theorists have adopted behavioral game-theoretic models to unpack, and quantify altruism, fairness, and cooperation (see Camerer, 2003). The dictator game has been used extensively to measure altruism toward non-kin in the laboratory (e.g., Heinz, Juranek, \& Rau, 2012; Hoffman, McCabe, \& Smith, 1996b). Game theory has proved useful in explaining how behavior has evolved in humans, suggesting economic strategy can assist in explaining evolved adaptations (Maynard, 1982). The dictator game is a simple allocation exercise involving a dictator and a recipient. The dictator is given an endowment that he or she can distribute with the recipient, or not; the dictator determines the proportion to be distributed, and the recipient's role is passive. The dictator game offers an extended choice set where dicta-tors can choose to keep the whole endowment, which is not possible when playing alternative economic games such as the ultimatum game (Cappelen, Nielsen, Sorensen, Tungodden, \& Tyran, 2013). The dictator game enables researchers to test simple predictions and identify predictors of altruism within a variety of contexts and populations (Benenson, Pascoe, \& Radmore, 2007).

The limited literature testing the hypothesis that physical attractiveness influences altruism in a face-to-face game-theoretic context has involved participants playing 
the ultimatum game. The ultimatum game is a two-person game involving a proposer and responder. The proposer is given an endowment to share with the responder. Once an offer is made to the responder, he or she accepts or rejects the offer. If the responder rejects, neither participant receives any of the stake, making the game strategic in nature. As well as a financial cost, there is also a social cost to not cooperating in the ultimatum game, as rejecting offers reduce one's chances of being chosen for future interactions (Andre \& Baumard, 2011). On the other hand, the dictator game is a game that measures altruism without there being an immediate cost to not being fair. Camerer (2003) argued that the dictator game measures altruism more directly than the ultimatum game, making it a suitable choice to test our hypotheses. Furthermore, fair behavior can evolve in the ultimatum game due to repeated interactions, whereas reciprocity is not a direct issue in a one-round dictator game (Debove, Baumard, \& Andre, 2016).

Saad and Gill (2001) found that physical attractiveness had no influence on altruism or cooperation when playing a face-to-face ultimatum game. However, men offered more of their stake to women. More recently, Bhogal, Galbraith, and Manktelow (2016b) investigated the role of physical attractiveness in altruism and cooperation in a face-to-face ultimatum game. They found men and women behaved fairly towards opposite sex responders, irrespective of their attraction to the recipient. However, decisions made in the ultimatum game are driven by strategy, especially as there is a risk to not being fair (Eckel \& Grossman, 1998). Due to this risk, the proposer's decisions are largely based on whether the responder accepts an offer, or not. Bhogal et al. (2016b) also found that the majority of responders accepted offers made by the proposer. To our knowledge, this article is the first to measure the influence of physical attractiveness on altruism when playing a dictator game, when dictators can physically see the recipient.

From the evidence discussed, we expected dictators (across Studies 1 and 2), particularly men, to offer more of a given stake to female recipients they considered attractive. We were also interested in the relationship between self-rated attractiveness and altruism. Shinada and Yamagishi (2014) conducted a study in which participants played a prisoner's dilemma game, with photographs. They found that the least attractive men displayed higher levels of cooperativeness compared to those who considered themselves as highly attractive. Less attractive men are argued to secure long-term reproductive success by gathering resources, more than highly attractive men, both adopting different strategies when attracting mates (Shinada \& Yamagishi, 2014).
Several studies have found that self-rated attractiveness strongly influences how we behave with others (Hill \& Reeve, 2004; Montoya, 2008). For example, Stirrat, Gumert, and Perrett (2011) investigated the relationship between self-rated attractiveness, the attractiveness of prospective partners, and paying for meals during mate formation. The authors found that men preferred to pay for meals with attractive women and that attractive women preferred attractive men to pay for their meals. In sum, they found that attractive participants were less willing to pay for meals compared to the least attractive participants. Furthermore, women were more interested in engaging with attractive men who paid for their meal, suggesting altruism, through resource sharing, may be a courtship display. The aforementioned research forms a rationale for including self-rated attractiveness in our design.

\section{Study 1 \\ Method $^{2}$ \\ Participants and design}

Two hundred twelve participants took part (106 dicta-tors, 106 recipients; $M$ age à $21, S D$ à 2.21). Sixty-five percent of the sample were single, and $35 \%$ were in a relationship. In an attempt to reduce the effects of social desirability and reputation effects between participants, efforts were made to recruit participants who did not know each other. Dictators were asked to rate how well they knew the recipient with whom they were paired on a 1 (not familiar) to 7 (very familiar) Likert scale. The mean score for familiarity in Study 1 was 1.3 (SD à .53). To reduce reputation management effects between dicta-tors and the experimenter, the dictator's allocations were anonymous. We adopted a correlational design where we conducted Pearson's correlation analysis between the dictators' perceived attractiveness of the recipient, self-rated attractiveness, and altruism, measured via the number of chocolate coins offered to the recipient.

\section{Materials and procedure}

Dictators were paired with different recipients of the opposite sex (e.g., male dictator, female recipient and vice versa). The study took place in a lab with a one way-mirror, which separates two experimental rooms. The dictator sat on the side from which he or she could see the recipient (through the mirror), and the recipient sat on the opposite side of the one-way mirror, where he or she could not see the dictator. As a result, dictators were able to allocate their stake anonymously. Ten chocolate coins were used as the monetary incentive, consistent with Bhogal et al. (2016b). 
Participants played a one-round dictator game as follows: The dictator was given 10 chocolate coins, that he or she could distribute with the recipient, or not. To ensure that dictators allocated anonymously, we left envelopes in the experimental room for the dictator to allocate his or her own stake and the recipient's stake. As altruism increases when people know they are being observed (e.g., Milinski, Semmann, \& Krambeck, 2002), the experimenter was not present in the room while the dictator allocated the coins but returned once the dictator signaled (by a knock on the door) that he or she had completed the game. Note that the dictator was aware that the recipient could not see him or her, and the recipient was aware that the dictator was of the opposite sex. After allocating the chocolate coins, dictators completed a questionnaire stating how attractive they considered the recipient on a 1 (very unattractive) to 7 (very attractive) Likert scale (consistent with Bhogal et al., 2016b). The questionnaire was sealed in an envelope to ensure anonymity. The coins left for the recipient were included in a separate envelope, which was then placed in a sealed box.

\section{Results}

Dictators offered an average of five out of 10 chocolate coins to the recipient ( $M$ à 4.99, $S D$ à 0.29). Table 1 provides descriptive statistics, and Table 2 provides correlation coefficients for key variables, respectively (data reported by sex).

A Pearson correlation coefficient was computed to assess the relationship between the number of chocolate coins offered to the recipient and the dictators perceived attractiveness of the recipient. There was no correlation between the two variables, for both male and female dictators. See Figure 1 (male dictators) and Figure 2 (female dictators) for a scatterplot outlining the relationship between allocations and perceived attractiveness. ${ }^{3}$

There was no correlation between allocations and the dictators self-rated attractiveness. There was a negative, medium correlation between the female dictators' self-

Table 1. Descriptive statistics for key variables, by sex (Study 1).

\begin{tabular}{lcccc} 
Variables & Sex of dictator & $\mathrm{M}$ & $\mathrm{SD}$ & $\mathrm{n}$ \\
\hline Dictators attraction to recipient & Male & 5.30 & 1.69 & 50 \\
& Female & 3.70 & 1.12 & 56 \\
Dictators self-rated attractiveness & Male & 3.90 & 1.10 & 50 \\
& Female & 5.10 & 1.12 & 56 \\
No. of chocolate coins offered & Male & 5.02 & 0.32 & 50 \\
to the recipient & Female & 4.97 & 0.27 & 56 \\
\hline
\end{tabular}

Table 2. Correlations between key variables, by sex (Study 1).

\begin{tabular}{|c|c|c|c|}
\hline & $\begin{array}{l}\text { 1. No. of coins offered } \\
\text { to the recipient }\end{array}$ & $\begin{array}{l}\text { 2. Attraction } \\
\text { to recipient }\end{array}$ & $\begin{array}{l}\text { 3. Self-rated } \\
\text { attractiveness }\end{array}$ \\
\hline $\begin{array}{l}1 \\
2\end{array}$ & $\overline{r a ̀ .18}$ & $\begin{array}{c}\mathrm{r} \text { à } " .04 \\
-\end{array}$ & $\begin{array}{l}\text { r à.18 } \\
\text { r à ".49 }\end{array}$ \\
\hline 3 & rà.19 & rà 13 & - \\
\hline
\end{tabular}

rated attractiveness and their perceived attractiveness of the male recipient.

\section{Discussion}

We find that the allocations made by male and female dictators were not influenced by the recipient's physical attractiveness or the dictator's self-rated attractiveness. Participants were consistently fair with recipients by offering half of the stake. Our finding is inconsistent with previous research outlined in the introduction, strongly challenging the literature. However, the find-ings are consistent with research adopting a similar design to ours, using the ultimatum game (e.g., Bhogal et al., 2016b).

We attempted to control for social desirability by ensuring participants allocated anonymously. However, participants behaved fairly, even when they were not identifiable. It is possible that this may be due to the stake involved and the fact that dictators did not actually earn their endowment. Of interest, we find that selfrated attractiveness does influence how we rate others on attractiveness, consistent with the literature, particularly among women (Montoya, 2008).

Traditional economic games involve a stake that is freely given to participants without any effort, which is rare in the real world (Wright, 1999). Participants may see themselves as having more rights over endowments they have actually earned (Baumard, Andre, \& Sperber, 2013; Cappelen et al., 2013). Dictators' allocations may be dependent upon their perception of whether they have the right to distribute the monetary stake (Hoffman et al., 1994; see List \& Cherry, 2008; Ruffle, 1998; Wu, Hu, van Dijk, Leliveld, \& Zhou, 2012). A possible reason for the noneffects found in Study 1 is that participants were not "playing" with a resource they had actually earned. When we discuss parental investment, it is in relation to the investment each sex makes toward their offspring. Keeping this point in mind, men may make a conscious effort only when deciding to distribute their resources, rather than hypothetical stakes, which may not hold as much value as actual money. As a result, chocolate coins were replaced with $£ 5$ (five £1 pound coins). 


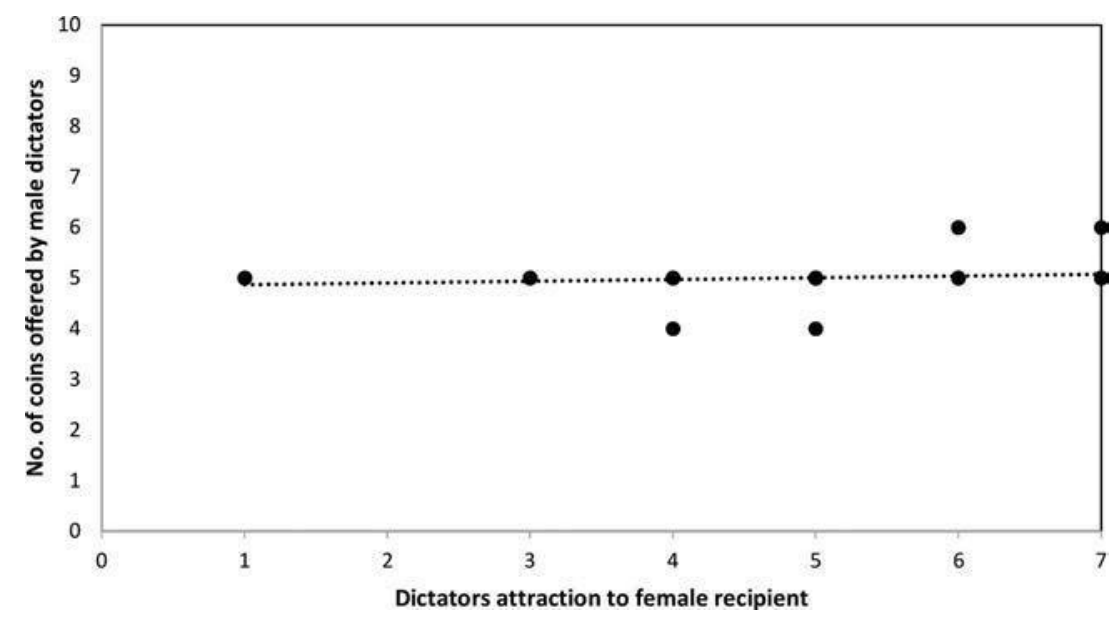

Figure 1. Scatterplot depicting the relationship between the number of coins offered by male dictators and their perceived attractiveness of the female recipient (Study 1 ).

Cherry, Frykblom, and Shogren (2002), adopting a quiz-based dictator game, found that those who earned their stake through taking part in a quiz distributed far more selfishly than those who were simply given their endowment. There appears to be a difference between equity (reward should correlate with effort) and equality (everyone should get an equal stake). Research does support the notion of equity in dictator game research, where dictators offer more to those they believe deserve the endowment (Eckel \& Grossman, 1996; Heinz et al., 2012). In addition, Oxoby and Spraggon (2008) conducted a study in which dictators and recipients earned their endowment by taking part in an exam. When dictators were simply given a stake, they offered $20 \%$ to recipients. However, dictators who earned their stake kept the whole endowment to themselves. Furthermore, when recipients earned their money, dictators offered them on average $50 \%$ of the stake. There is a link between contribution, effort, entitlement, and profit (Bardsley, 2008; Guo et al., 2014; Lesorogol, 2014).

\section{Study 2}

\section{Method}

\section{Participants and design}

One hundred eighty-eight participants took part (94 dictators, 94 recipients; $M$ age à $19, S D$ à 0.76 ). Eighty percent were single, and $20 \%$ were dating. Consistent with Study 1, dictators were asked to rate how well they knew the recipient with whom they were paired ( $M$ familiarity rating à $1.1, S D$ à .28). Study 2 was simi-lar to Study 1 , with some changes made to the materials and procedure, outlined next.

\section{Materials and procedure}

We altered the design and asked participants to play a dictator game face-to-face. However, we still wanted to

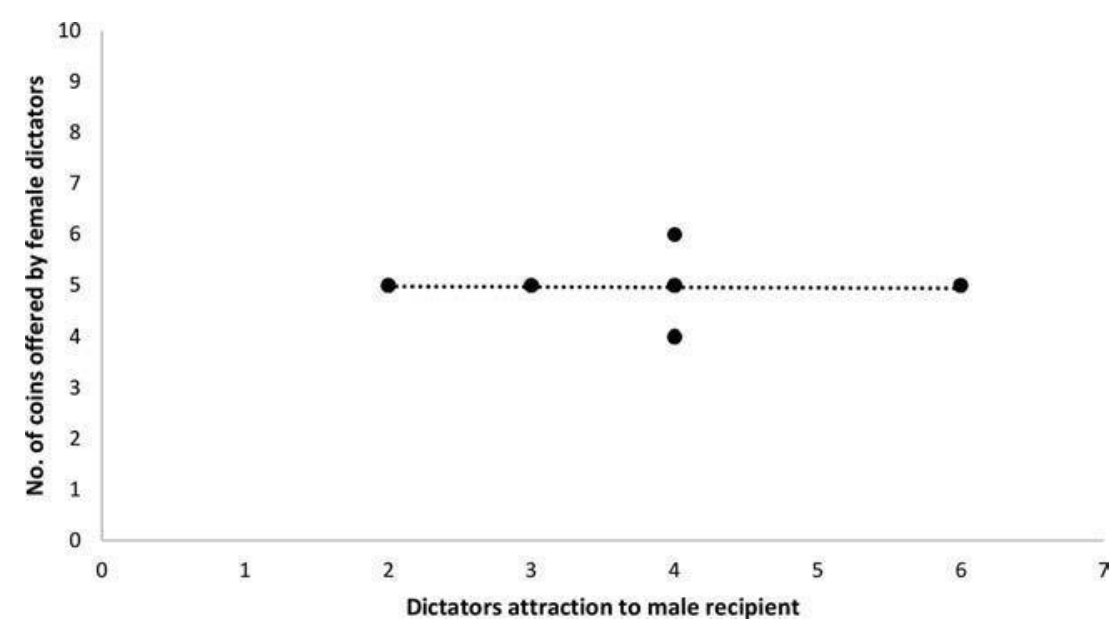

Figure 2. Scatterplot depicting the relationship between the number of coins offered by female dictators and their perceived attractiveness of the male recipient (Study 2). 
ensure that impression management did not influence how many pounds coins the dictator offered the recipi-ent. As a result, dictators did not allocate the stake in front of the recipient or experimenter. Both participants (one man, one woman) completed all relevant ethical forms in the same room, as this gave the participants an opportunity to observe the other participant. They then took part in a quiz, after which the recipient was told that he or she did not win, and was then debriefed outside the room.

Once the recipient left the experimental lab, the dictator was given £5 (five £1 coins) and envelopes to allocate his or her own and the recipient's stake. We used $£ 5$ to enforce forced-choice. The experimenter then left the room, after which the dictator allocated the amount, consistent with Study 1. The experimenter returned and asked the dictator to complete the attract-iveness questionnaire used in Study 1 and to place it in one of the sealed envelopes, and then into a sealed box, anonymously.

\section{Results}

Dictators offered an average of $£ 3$ coins ( $S D$ à 0.31 ) to the recipient and kept £2 ( $S D$ à 0.21) for themselves. We found that when participants were faced with forced choice, they behaved altruistically, offering more to the recipient than they kept. Table 3 provides descriptive statistics, and Table 4 provides correlation coefficients for key variables (data reported by sex).

A Pearson correlation coefficient was computed to assess the relationship between the number of pound coins offered to the recipient and the dictators perceived attractiveness of the recipient. Consistent with Study 1, there was no correlation between the two variables for both male and female dictators. See Figure 3 (male dictators) and Figure 4 (female dictators) for a scatterplot outlining the relationship between allocations and perceived attractiveness. Consistent with Study 1, there was a negative, medium correlation between the female dictators self-rated attractiveness and their perceived attractiveness of the male recipient.

Table 3. Descriptive statistics for key variables, by sex (Study 2).

\begin{tabular}{lcccc} 
Variables & Sex of dictator & $\mathrm{M}$ & $\mathrm{SD}$ & $\mathrm{n}$ \\
\hline Dictators attraction to recipient & Male & 5.10 & 1.80 & 46 \\
& Female & 3.70 & 1.13 & 48 \\
Dictators self-rated attractiveness & Male & 3.93 & 1.64 & 46 \\
& Female & 4.90 & 1.85 & 48 \\
No. of £1 coins offered to & Male & 3.00 & 0.30 & 46 \\
the recipient & Female & 3.00 & 0.33 & 48 \\
\hline
\end{tabular}

Table 4. Correlations between key variables, by sex.

\begin{tabular}{|c|c|c|c|}
\hline & $\begin{array}{c}\text { 1. No. of } \\
\text { coins offered }\end{array}$ & $\begin{array}{l}\text { 2. Attraction } \\
\text { to recipient }\end{array}$ & $\begin{array}{l}\text { 3. Self-rated } \\
\text { attractiveness }\end{array}$ \\
\hline 1 & - & r à ".13 & r à ".07 \\
\hline 2 & r à .04 & - & r à ".50 \\
\hline 3 & rà.09 & r à ".02 & - \\
\hline
\end{tabular}

\section{General discussion}

We found that when playing modified dictator games, there was no relationship between the perceived attractiveness of the recipient and the number of coins offered. The findings of Study 2 were more surprising than Study 1 , as participants earned the stake they distributed. We found that when manipulating stakes and anonymity between participants, dictators behaved fairly, and altruistically, irrespective of their perceived attractiveness of the recipient. In sum, attractiveness had no influence on how dictators allocated their stakes. Bhogal et al. (2016b) argued that participants behave fairly when playing economic games because fairness signals equality as opposed to favorability.

Our findings are inconsistent with previous research using facial images and vignettes, where participants are more altruistic toward those they find attractive. Our research deviated from traditional game-theoretic research using facial images and hypothetical scenarios. For example, Saad and Gill (2001) and Bhogal et al. (2016b) adopted designs dissimilar to traditional research within the field, thus being unable to replicate the effects of attractiveness on altruism found in previous literature. We used the dictator game because it is nonstrategic, unlike the ultimatum game. We expected the nonstrategic nature of the dictator game to elicit similar findings to previous literature that sup-ports the sexual selection hypothesis in explaining altruism within a gametheoretic framework. However, we find no support for altruism being a courtship display.

From the studies outlined in this article, men and women were not behaving in a manner predicted by sexual selection (in relation to altruism) or behavioral game theory (maximizing personal payoffs). Instead, men and women behaved fairly, uninfluenced by their own or their perceived attractiveness of the recipient. Our findings, coupled with the limited literature (e.g., Bhogal et al., 2016b; Saad \& Gill, 2001), strongly chal-lenge the assumptions and the findings of the literature suggesting altruism is a courtship display evolved to attract the opposite sex. Typically, even when attractive-ness has no influence on altruism, men have been found to be more altruistic toward women (e.g., Saad \& Gill, 2001), which our findings also challenge. As a result, 


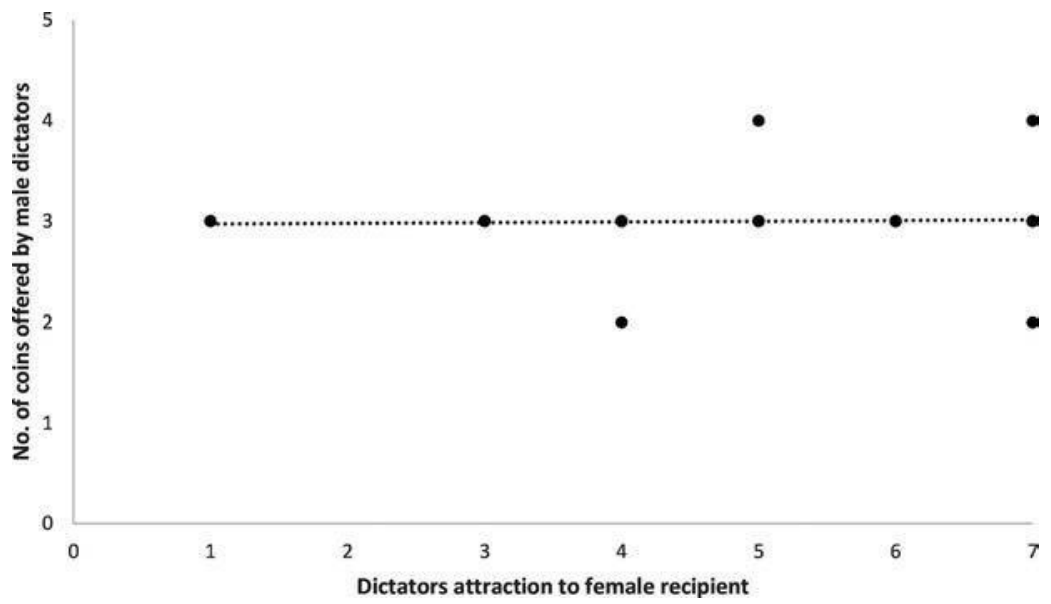

Figure 3. Scatterplot depicting the relationship between the number of coins offered by male dictators and their perceived attractiveness of the female recipient (Study 2).

our results could be quite damaging to the presumptions of evolutionary theorists exploring the influence of physical attractiveness on altruism in economic games, using the framework of sexual selection theory.

We provide clear evidence that altruism is in no way influenced by physical attractiveness when players are engaging with "live" participants. A strength of our studies relates to the design. The dictator game offers researchers a paradigm under which we can isolate and measure individual predictors of altruistic behavior (Bechler, Green, \& Myerson, 2015).

However, one of the major disadvantages of observing altruistic behavior in the lab relates to external validity (Winking \& Mizer, 2013). Researchers argue that the issue relates to participants behaving as though they are being observed, due to the experimental framework of research utilizing economic games, such as the presence of researchers and anonymity (Fessler, 2009; Haley \& Fessler, 2005; Winking \& Mizer, 2013). However, we did aim to control for such variables by ensuring anonymity between participants and the dictator/experimenter. However, human beings have evolved mechanisms whereby we see social exchanges as potential long-term relationships, particularly as our ancestors lived in close proximate groups, where anonymity was not always possible (Cosmides \& Tooby, 2005), which may also explain the prevalence of fairness across both studies, especially as participants were engaging with "live" participants.

We set out to investigate whether physical attractiveness influenced altruism in modified dictator games. However, we found that physical attractiveness does

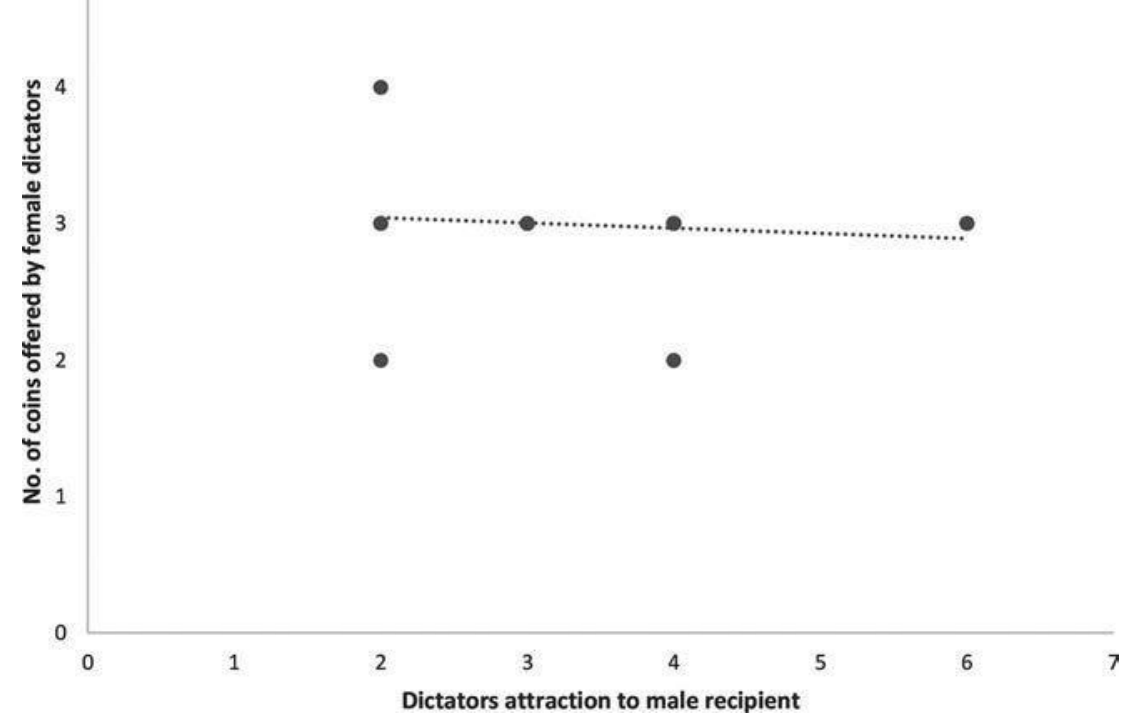

Figure 4. Scatterplot depicting the relationship between the number of coins offered by female dictators and their perceived attractiveness of the male recipient (Study 2). 
not influence altruistic behavior, even though there is a beauty premium for which attractive people are thought to be "better" than unattractive individuals and have been found to be offered more in economic games com-pared to unattractive people. It is rather difficult to investigate whether the fair behavior observed in both studies is a reflection of reputation management or the strategic nature of economic games (Eckel \& Grossman, 1998). Furthermore, Nettle et al. (2013) argued that economic games involving low stakes yield a high pro-portion of participants sharing their stake, which could be a potential explanation for our findings. Perhaps future research needs to be conducted where dictators are given, or have the chance to earn larger stakes.

Fairness appeared to be a powerful driver of how participants allocated their stake. It appears that being both selfish and altruistic is not seen as a normative behavior, which may be why participants were consistently fair. People appear to have a need to appear to be fair and equal (Benabou \& Tirole, 2006). Fairness implies impartiality (Baumard, Andre, \& Sperber, 2013), which appears to be driven by prosocial norms (Skyrms, 2014). A reason why participants were fair may be because they were adhering to social norms of fairness, especially as people rely on fairness norms when bargaining in economic games (Skyrms \& Zollman, 2010). According to Skyrms (2014), we are acculturated into incorporating fairness into our everyday decision making.

Young (2015) suggested that social norms drive behavior that signals morality. Social norms help to resolve collective conflict, and Young suggested that the 50/50 division is a social norm because it is a prominent solution in everyday situations. Furthermore, Young suggested that norms signal intention, and one's moral character, which can be beneficial at a reputational level. Therefore, fairness is a social norm, as it signals equality. Fairness norms may therefore moderate altruistic or coop-erative behavior (Debove et al., 2016; Yamamoto \& Taki-moto, 2012). This battle between behaving fairly, selfishly, or altruistically may be influenced by the fact that altruism can often leave the altruist with a lower payoff than the recipient, whereas fairness equalizes social exchange.

According to Mercier and Sperber (2011), evolution may have selected cognitive mechanisms that force us to adhere to norms that increase our fitness. Fairness is social norm, especially as fairness links to cooperation, social exchange, and reciprocity. Inequality aversion refers to when people are willing to receive lower or higher payoffs to achieve equitable outcomes (Montero, 2007). Being unfair is not seen to be equitable, whether it relates to disadvantageous or advantageous inequality aversion (see Fehr \& Schmidt, 1999). Participants in Studies 1 to 2 appeared to value equality, motivated by the avoidance of disutility. People are motivated by fair, equal outcomes and are willing to receive a lower payoff in order to promote equality (Dawes, McTavish, \& Shaklee, 1977). As a result, inequality aversion can be avoided by adopting fairness norms (Yamamoto \& Takimoto, 2012). Research suggests that people prefer equal outcomes (Fehr \& Schmidt, 1999). In support, Skyrms (2014) argued that fairness (50/50 distribution) is an evolutionarily stable strategy, which may be why previous research, including our results, has found that people generally distribute stakes fairly when playing economic games.

According to Nowak, Page, \& Sigmund (2000), reputation is fundamental to the evolution of fairness norms. Fairness evolves in economic games, because there is much to gain through reciprocal fairness. Chiang (2008) also applied reputation models to explain the evolution of fairness. He argued that a preference for fairness is built on the fact that benefits accumulated through fairness, if large enough, should evolve in a given population. Andre and Baumard (2011), adopting a partner choice framework and a reputation-based model, found that when people had the opportunity to choose partners in an economic game, they chose those who adhere to fairness norms.

Our research has some notable limitations. First, the resources varied between each study. People might have behaved differently if the stakes were larger and if these stakes had higher monetary value. Although the rationale for changing the stakes was that participants may view money as having more value than chocolate, we found that this was not the case. Perhaps future research could increase the stakes available. Second, we limited the framework to a dictator game. Perhaps future research could investigate whether physical attractiveness influences altruism in trust and public goods games. Although researchers have argued that maintaining anonymity is important in reducing reputation management effects (e.g., Franzen \& Pointner, 2012), this article provides evi-dence that increasing anonymity between participants, and between experimenter/dictator, has no influence on altruistic behavior, thus strongly challenging previous research in the field. As Winking and Mizer (2013) stated, "Despite assurances of anonymity, participants must still somehow record their decision with the knowledge that it will be reviewed and analysed" (p. 289). Therefore, the impact of reputation management and social desirability may have still been present even when the dictator was not face-to-face with the recipient. Some may argue that manipulating stakes was a limitation. However, previous research suggests that when comparing offers in studies using genuine, or replica money, offers tend to be similar (Ben-Ner, Kramer, \& Levi, 2008; Gillis \& Hettler, 2007) 
regardless of initial levies on stakes (Hoffman, McCabe, \& Smith, 1996a).

Traditional game theory suggests that decision making is purely rational; we make decisions that increase our personal payoffs. If that were the case, participants should have offered less to others when given the chance to do so. However, there is some contention that players see economic games as moral dilemmas, as opposed to economic transactions, thus leading players to behave moralistically as opposed to maximizing personal profit (see Baumard, 2016). This may be why attractiveness had no influence on altruism in the framework we adopted.

In sum, the studies reported in this article do not provide support for the sexual selection hypothesis as an explanation for the evolution of altruism, particularly when participants play economic games where they can see the other participant, in person. Instead, we find that fairness, or fairness norms, appear to drive people's decision making when playing economic games. Further testing is needed to explore the relationship between altruism and physical attractiveness in a wider variety of contexts; however, this article strongly challenges the assumptions and findings within the field.

\section{Notes}

1. Terms such as altruism, fairness, and generosity are used loosely and interchangeably within the field. We follow the guidelines of West et al. (2011) and Debove et al. (2016) by using the terms more stringently. In game-theoretic terms, we define altruism as offering more to a recipient than one keeps. We refer to fairness when parti-cipants distribute a stake equally by offering half an endowment to another participant (50/50 split).

2. Both studies were approved by the research ethics commit-tee at the University of Wolverhampton. All participants across Studies 1 and 2 were recruited from the University of Wolverhampton. Note that it was a prerequisite that participants who took part in Study 1 were not permitted to take part in Study 2.

3. We believe, consistent with Valentine, Aloe, and Lau (2015), that graphical displays of data provide the reader with a better understanding of the results.

\section{References}

Anderson, M. (1994). Sexual selection. Princeton, NJ: Princeton University Press.

Andre, J., \& Baumard, N. (2011). Social opportunities and the evolution of fairness. Journal of Theoretical Biology, 289, 128-135. doi:10.1016/j.jtbi.2011.07.031

Andreoni, J., \& Petrie, R. (2008). Beauty, gender and stereotypes: Evidence from laboratory studies. Journal of Economic Psychology, 29, 73-93. doi:10.1016/j.joep.2007. 07.008
Bak, P. M. (2010). Sex differences in the attractiveness halo-effect in the online dating environment. Journal of Business and Media Psychology, 1, 1-7.

Baldwin, M. W. (1992). Relational schemas and the processing of social information. Psychological Bulletin, 112, 461-484. doi:10.1037/0033-2909.112.3.461

Barclay, P. (2010). Altruism as a courtship display: Some effects of third-party generosity on audience perceptions. British Journal of Psychology, 101, 123-135.

Bardsley, N. (2008). Dictator game giving: Altruism or arte-fact. Experimental Economics, 11, 122-133. doi:10.1007/ s10683-007-9172-2

Baumard, N. (2016). The origins of fairness: How evolution explains our moral nature. New York, NY: Oxford University Press.

Baumard, N., Andre, J., \& Sperber, D. (2013). A mutualistic approach to morality: The evolution of fairness by partner choice. Behavioral and Brain Sciences, 36, 59122. doi:10.1017/s0140525 $\rightarrow 11002202$

Bechler, C., Green, L., \& Myerson, J. (2015). Proportion offered in the dictator and ultimatum games decreases with amount and social distance. Behavioural Processes, 115, 149-155. doi:10.1016/j.beproc.2015.04.003

Benabou, R., \& Tirole, J. (2006). Incentives and prosocial behaviour. American Economic Review, 96, 1652-1678. doi:10.1257/aer.96.5.1652

Benenson, J. F., Pascoe, J., \& Radmore, N. (2007). Children's altruistic behavior in the dictator game. Evolution and Human Behavior, 28, 168-175. doi:10.1016/j.evolhumbehav. 2006.10.003

Ben-Ner, A., Kramer, A., \& Levi, A. (2008). Economic and hypothetical dictator game experiments: Incentive effects at the individual level. Journal of Socio-Economics, 37, 1775-1784. doi:10.1016/j.socec.2007.11.004

Bhogal, M. S., Galbraith, N., \& Manktelow, K. (2016a). Sexual selection and the evolution of altruism: Males are more altruistic and cooperative towards attractive females. Letters on Evolutionary Behavioral Science, 7, 10-13. doi:10.5178/ lebs.2016.42

Bhogal, M. S., Galbraith, N., \& Manktelow, K. (2016b). Physical attractiveness, altruism and cooperation in an ultimatum game. Current Psychology. Advance online publication. doi:10.1007/s12144-016-9443-1

Brase, G. L. (2006). Cues of parental investment as a factor in attractiveness. Evolution and Human Behavior, 27, 145-157.

Buss, D. M. (1989). Sex differences in human mate preferences: Evolutionary hypotheses testing in 37 cultures.

Behavioral and Brain Sciences, 12, 1-49. doi:10.1017/ s0140525 $\rightarrow 00023992$

Camerer, C. F. (2003). Behavioral game theory. Princeton, NJ: Princeton University Press. Cappelen, A. W., Nielsen, U. H., Sorensen, E., Tungodden, B., \& Tyran, J.-R. (2013). Give and take in dictator games. Econ-omic Letters, 118, 280-283. doi:10.1016/j.econlet.2012.10.030 Cherry,

T. L., Frykblom, P., \& Shogren, J. F. (2002). Hard nose the dictator. American Economic Review, 92(4), 1218-1221. Chiang, Y. S. (2008). A path towards fairness: Preferential association and the evolution of strategies in the ultimatum game. Rationality and Society, 20, 173-201.

Cosmides, L., \& Tooby, J. (2005). Neurocognitive adaptations designed for social exchange. In D. M. Buss (Ed.), 
The handbook of evolutionary psychology (pp. 584627). Hoboken, NJ: Wiley.

Dawes, R. M., McTavish, J., \& Shaklee, H. (1977). Behavior, communication, and assumptions about other people's behavior in a common dilemma situation. Journal of Personality and Social Psychology, 35, 1-11. doi:10.1037/ 0022-3514.35.1.1

Debove, S., Baumard, N., \& Andre, J. B. (2016). Models of the evolution of fairness in the ultimatum game: A review and classification. Evolution and Human Behavior, 37, 245-254. doi:10.1016/j.evolhumbehav.2016.01.001

Dion, K., Berscheid, E., \& Walster, E. (1972). What is beautiful is good. Journal of Personality and Social Psychology, 24, 285-290. doi:10.1037/h0033731

Eagly, A. H., \& Crowley, M. (1986). Gender and helping behavior: A meta-analytic review of the social psychological literature. Psychological Bulletin, 100, 283-308. doi:10.1037/ 0033-2909.100.3.283

Eckel, C. C., \& Grossman, P. J. (1996). Altruism in anonymous dictator games. Games and Economic Behavior, 16, 181-191.

Eckel, C. C., \& Grossman, P. J. (1998). Are women less selfish than men? Evidence from dictator experiments. The Econ-omic Journal, 108, 726-735. doi:10.1111/1468-0297.00311

Eckel, C. C., \& Grossman, P. J. (2001). Chivalry and solidarity in ultimatum games. Economic Enquiry, 39(2), 171-188. doi:10.1093/ei/39.2.171

Farrelly, D. (2011). Cooperation as a signal of genetic of phenotypic quality in female mate choice? Evidence from preferences across the menstrual cycle. British Journal of Psychology, 102, 406-430. doi:10.1348/000712610 $\rightarrow 532896$ Farrelly, D. (2013). Altruism as an indicator of good parenting quality in long-term relationships: Further investigations using the mate preferences towards altruistic traits scale. The Journal of Social Psychology, 153, 395-398. doi:10.1080/ 00224545.2013.768595

Farrelly, D., Clemson, P., \& Guthrie, M. (2016). Are women's mate preferences for altruism also influenced by physical attractiveness? Evolutionary Psychology, 14, 1-6. doi:10.1177/ 1474704915623698

Farrelly, D., Lazarus, J., \& Roberts, G. (2007). Altruists attract. Evolutionary Psychology, 5, 313-329. doi:10.1177/14747049 0700500205

Fehr, E., \& Schmidt, K. M. (1999). A theory of fairness, competition, and cooperation. Quarterly Journal of Economics, 114, 817-868. doi:10.1162/003355399556151

Fessler, D. M. T. (2009). Return of the lost letter. Experimental framing does not enhance altruism in an everyday context. Journal of Economic Behavior and Organization, 71, 575-578.

Fontelle, G. A., Phillips, A. P., \& Lane, D. (1985). Generalising across stimuli as well as subjects: A neglected aspect of external validity. Journal of Applied Psychology, 70(1), 101107. doi:10.1037/0021-9010.70.1.101

Franzen, A., \& Pointner, S. (2012). Anonymity in the dictator game revisited. Journal of Economic Behavior \& Organization, 81, 74-81. doi:10.1016/j.jebo.2011.09.005

Gillis, M. T., \& Hettler, P. L. (2007). Hypothetical and real incentives in the ultimatum game and Andreoni's public goods game: An experimental study. Eastern Economic Journal, 33, 491-510.

Goldberg, T. L. (1995). Altruism towards panhandlers: Who gives? Human Nature, 6, 79-89. doi:10.1007/bf02734137
Guo, X., Zheng, L., Cheng, X., Chen, M., Zhu, L., \& Li, J. (2014). Neural responses to unfairness and fairness depend on selfcontribution to the income. Social Cognitive and Affective Neuroscience, 9, 1498-1505. doi:10.1093/scan/nst131

Haley, K. J., \& Fessler, D. M. T. (2005). Nobody's watching? Subtle cues affect generosity in an anonymous economic game. Evolution and Human Behavior, 26, 245-256.

Hamilton, W. D. (1963). The evolution of altruistic behavior. American Naturalist, 97, 354-356. doi:10.1086/497114

Heinz, M., Juranek, S., \& Rau, H. A. (2012). Do women behave more reciprocally than men? Gender differences in real effort dictator games. Journal of Economic Behavior \& Organization, 83, 105-110. doi:10.1016/j.jebo.2011.06.015

Hill, S. E., \& Reeve, H. K. (2004). Mating games: The evol-ution of human mating transactions. Behavioral Ecology, 15, 748-756.

Hoffman, E., McCabe, K., Shackat, K., \& Smith, V. (1994). Preference, property rights and anonymity in bargaining games. Games and Economic Behavior, 7, 346-380.

Hoffman, E., McCabe, K., \& Smith, V. L. (1996a). On expectations and the monetary stakes in ultimatum games. International Journal of Game Theory, 25, 289-301. doi:10.1007/bf02425259

Hoffman, E., McCabe, K., \& Smith, V. L. (1996b). Social distance and other-regarding behavior in dictator games. American Economic Review, 86, 653-660.

Iredale, W., Van Vugt, M., \& Dunbar, R. (2008). Showing off in humans: Male altruism as a mating signal. Evolutionary Psychology, 6, 386-392. doi:10.1177/147470490800600302

Kahn, A., Hottes, J., \& Davis, W. L. (1971). Cooperation and optimal responding in the Prisoner's Dilemma game: Effects of sex and physical attractiveness. Journal of Personality and Social Psychology, 17, 267-279. doi:10.1037/h0030597

Kaplan, H., \& Hill, K. (1985). Food sharing among Ache foragers: Tests of explanatory hypotheses. Current Anthropology, 26, 223-246. doi:10.1086/203251

Kokko, H. (1998). Should advertising parental care be honest? Proceedings of the Royal Society of London B, 265, 1871-1878. doi:10.1098/rspb.1998.0515

Kurzban, R., Burton-Chellew, M. N., \& West, S. A. (2015). The evolution of altruism in humans. Annual Review of Psychology, 66, 575-599. doi:10.1146/annurev-psych-010814-015355

Langlois, J. H., Kalakanis, L., Rubenstein, A. J., Larson, A., Hallam, M., \& Smoot, M. (2000). Maxims or myths of beauty? A meta-analytic and theoretical review. Psychologi-cal Bulletin, 26, 390-423. doi:10.1037/0033-2909.126.3.390

Lesorogol, C. (2014). Gifts or entitlements: Gifts or entitlements: The influence of property rights and institutions for third-party sanctioning on behavior in dictator, ultimatum and punishment games. In J. Henrich \& J. Esminger

(Eds.), Experimenting with social norms: Fairness and punishment in cross-cultural perspective (pp. 357-375). New York, NY: Russell Sage.

List, J. A., \& Cherry, T. J. (2008). Examining the role of fairness in high stakes allocation decisions. Journal of Economic Behavior and Organization, 65, 1-8. doi:10.1016/ j.jebo.2003.09.021

Lorenzo, G. L., Biesanz, J. C., \& Human, L. J. (2010). What is beautiful is good and more accurately understood: Physical attractiveness and accuracy in first impressions of person-ality. Association for Psychological Science, 21, 1777-1782. doi:10.1177/0956797610388048 
Maestripieri, D., Henry, A., \& Nickels, N. (2016). Explaining financial and prosocial biases in favour of attractive people: Interdisciplinary perspectives from economics, social psychology, and evolutionary psychology. Behavioral and Brain Sciences, 1-76. doi:10.1017/s0140525x16000340

Maner, J. K., Kenrick, D. T., Becker, D. V., Delton, A. W., Hofer, B., Wilbur, C., \& Neuberg, S. (2003). Sexually selective cognition: Beauty captures the mind of the beholder. Journal of Personality and Social Psychology, 85, 1107-1120. doi:10.1037/0022-3514.85.6.1107

Maynard, S. J. (1982). Evolution and the theories of games. New York, NY: Cambridge University Press. Mercier, H., \& Sperber, D. (2011). Why do humans reason? Arguments for an argumentative theory. Behavioral and Brain Sciences, 34, 57-74. doi:10.1017/s0140525 $\rightarrow 10000968$ Milinski, M., Semmann, D., \& Krambeck, H. J. (2002). Reputation helps solve the 'strategy of the commons'. Nature, 415, 424-426. doi:10.1038/415424a

Miller, G. F. (2007). Sexual selection for moral virtues. Quarterly Review of Biology, 82, 97-125. doi:10.1086/517857

Montero, M. (2007). Inequity aversion may increase inequity. Economic Journal, 117, 192-204. doi:10.1111/j.14680297. 2007.02041.x

Montoya, R. M. (2008). I'm hot, so l'd say you're not: The influence of objective physical attractiveness on mate selection. Personality and Social Psychology Bulletin, 34, 1315-1331.

Mulford, M., Orbell, J., Shatto, C., \& Stockard, J. (1998).

Physical attractiveness, opportunity, and success in everyday exchange. American Journal of Sociology, 103, 1565-1592. doi:10.1086/231401

Nettle, D., Harper, Z., Kidson, Z., Stone, R., Penton-Voak, I. S., \& Bateson, M. (2013). The watching eyes effect in the dictator game: It's not how much you give, it's being seen to give something. Evolution and Human Behavior, 34, 35-40. doi:10.1016/j.evolhumbehav.2012.08.004 Nowak, M. A., Page, K. M., \& Sigmund, K. (2000). Fairness ver-

sus reason in the Ultimatum Game. Science, 289, 1773-1775. Oda, R., Shibata, A., Kiyonari, T., Takeda, M., \& MatsumotoOda, A. (2013). Sexually dimorphic preference for altruism in the opposite sex according to the recipient. British Journal of Psychology, 104, 577-584. doi:10.1111/bjop.12021 Oxoby, R. J., \& Spraggon, J. (2008). Mine and yours: Property rights in dictator games. Journal of Economic Behavior and Organization, 65, 703-713. doi:10.1016/j.jebo.2005.12.006 Phillips, T., Barnard, C., Ferguson, E., \& Reader, T. (2008). Do humans prefer altruistic mates? Testing a link between sexual selection and altruism towards non-relatives. British Journal of Psychology, 99, 555-572. doi:10.1348/000712608 $\rightarrow 298467$

Rosenblat, T. S. (2008). The beauty premium: Physical attractiveness and gender in dictator games. Negotiation Journal, 24, 465-481. doi:10.1111/j.1571-9979.2008.00198.x Ruffle, B. J. (1998). More is better, but fair is fair: Tipping in dictator and ultimatum games. Games and Economic Behavior, 23, 247-265. doi:10.1006/game.1997.0630

Saad, D., \& Gill, T. (2001). Sex differences in the ultimatum game: An evolutionary psychology perspective. Journal of Bioeconomics, 3, 171-193.

Shinada, M., \& Yamagishi, T. (2014). Physical attractiveness and cooperation in a prisoner's dilemma game. Evolution and Human Behavior, 35, 451-455. doi:10.1016/j. evolhumbehav.2014.06.003
Skyrms, B. (2014). Evolution of the social contract. New York, NY: Cambridge University Press.

Skyrms, B., \& Zollman, K. (2010). Evolutionary considerations in the framing of social norms. Politics, Philosophy \& Economics, 9, 265-273. doi:10.1177/1470594 $\rightarrow 09339744$

Solnick, S. J., \& Schweitzer, M. E. (1999). The influence of physical attractiveness and gender on ultimatum game decisions. Organizational Behavior and Human Decision Processes, 79, 199-215. doi:10.1006/obhd.1999.2843

Stirrat, M., Gumert, M., \& Perrett, D. (2011). The effect of attractiveness on food sharing preferences in human mating markets. Evolutionary Psychology, 9(1), 79-91. doi:10.1177/147470491100900110

Tessman, I. (1995). Human altruism as a courtship display. Oikos, 74, 157-158. doi:10.2307/3545685

Trivers, R. L. (1971). The evolution of reciprocal altruism. Quarterly Review of Biology, 46, 35-57. doi:10.1086/406755

Trivers, R. L. (1972). Parental investment and sexual selection. In B. Campbell (Ed.), Sexual selection and the descent of man, 1871-1971 (pp. 136-179). Chicago, IL: Aldine.

Valentine, J. C., Aloe, A. M., \& Lau, T. S. (2015). Life after NHST: How to describe your data without "p-ing" everywhere. Basic and Applied Social Psychology, 37, 260-273. doi:10.1080/01973533.2015.1060240

Van Vugt, M., \& Iredale, W. (2013). Men behaving nicely: Public goods as peacock tails. British Journal of Psychology, 104, 313. doi:10.1111/j.2044-8295.2011.02093.x

West, S. S. A., Mouden, C. E., Gardner, A., \& Mouden, C. E. I. (2011). Sixteen common misconceptions about the evolution of cooperation in humans. Evolution and Human Behavior, 32, 231-262.

Winking, J., \& Mizer, N. (2013). Natural-field dictator game shows no altruistic giving. Evolution and Human Behavior, 34, 288-293. doi:10.1016/j.evolhumbehav.2013.04.002

Wood, B., \& Hill, K. (2000). A test of the "showing-off" hypothesis with ache hunters. Current Anthropology, 41, 124-125. doi:10.1086/300111

Workman, L., \& Reader, W. (2014). Evolutionary psychology (3rd ed.). New York, NY: Cambridge University Press.

Wright, J. B. (1999). Adam Smith on instincts, affection, and informal learning: Proximate mechanisms and multilevel selection. Review of Social Economy, 68, 95-113.

Wu, Y., Hu, J., van Dijk, E., Leliveld, M. C., \& Zhou, X. (2012). Brain activity in fairness consideration during asset distribution: does the initial ownership play a role? PLoS ONE, 7, e39627. doi:10.1371/journal.pone.0039627

Yamamoto, S., \& Takimoto, A. (2012). Empathy and fairness: Psychological mechanisms for eliciting and maintaining pro sociality and cooperation in primates. Social Justice Research, 25, 233-255. doi:10.1007/s11211-012-0160-0

Young, H. P. (2015). The evolution of social norms. Annual Review of Economics, 7, 359-387. doi:10.1146/annurev-economics-080614-115322

Zaatari, D., Palestis, B. G., \& Trivers, R. (2009). Fluctuating asymmetry of responders affects offers in the ultimatum game oppositely according to attractiveness or need as perceived by proposers. Ethology, 115, 627-632. doi:10.1111/j.1439-0310.2009.01648.x

Zahavi, A., \& Zahavi, A. (1997). The handicap principle: A missing part of Darwin's puzzle. Oxford, England: Oxford University Press. 